\title{
Efeito da adição de óxido de zinco e de óxido de boro nas propriedades do zirconato de bário dopado com ítrio
}

\author{
(Effect of zinc oxide and boron oxide addition on the properties of \\ yttrium-doped barium zirconate)
}

\author{
T. F. Andrade, R. Muccillo \\ Centro de Ciência e Tecnologia de Materiais - CCTM, Instituto de Pesquisas Energéticas e Nucleares - \\ IPEN, Travessa R 400, Cidade Universitária, S. Paulo, SP 05508-000 \\ muccillo@ipen.br
}

\begin{abstract}
Resumo
Compostos condutores protônicos de $\mathrm{BaZr}_{0,8} \mathrm{Y}_{0,2} \mathrm{O}_{3-\delta}$, preparados por síntese de estado sólido, foram compactados e sinterizados com $\mathrm{ZnO}$ e $\mathrm{B}_{2} \mathrm{O}_{3}$ como aditivos. Os corpos cerâmicos sinterizados foram analisados por difração de raios X e espectroscopia de impedância. Superfícies polidas e atacadas termicamente foram observadas em microscópio de varredura por sonda. As medidas de densidade mostraram que a maior densificação foi obtida com óxido de zinco nas proporções de 2 e 5 peso $\%$, atingindo aproximadamente $95 \%$ da densidade teórica. As medidas de resistividade elétrica evidenciaram a menor resistividade elétrica do composto cerâmico $\mathrm{BaZr}_{0,8} \mathrm{Y}_{0,2} \mathrm{O}_{3-\delta}$ com 5 peso \% de $\mathrm{ZnO}$. Os aditivos de sinterização, óxido de boro e óxido de zinco, foram eficientes para obter compostos com menores valores de resistividade elétrica que os obtidos em compostos sinterizados sem aditivos.

Palavras-chave: zirconato de bário, óxido de boro, óxido de zinco, espectroscopia de impedância, condutor protônico.
\end{abstract}

\begin{abstract}
$\mathrm{BaZr}_{0.8} \mathrm{Y}_{0.2} \mathrm{O}_{3-\delta}$ protonic conductors, prepared by the ceramic route, were pressed and sintered with $\mathrm{ZnO}$ and $\mathrm{B}_{2} \mathrm{O}_{3}$ sintering aids. The sintered pellets were analyzed by X-ray diffraction and impedance spectroscopy. Polished and thermally etched surfaces of the pellets were observed in a scanning probe microscope. The highest values of apparent density, 95\%T.D., were obtained with 2 and $5 \mathrm{wt. \%} \mathrm{ZnO}$. The lowest value of electrical resistivity was evaluated in the yttrium-doped barium zirconate compounds with $5 \mathrm{wt} \% \mathrm{ZnO}$. Boron oxide and zinc oxide sintering aids were efficient to improve the apparent density as well as the electrical conductivity of $B a Z r_{0.8} Y_{0.2} O_{3-\delta}$ protonic conductors.
\end{abstract}

Keywords: barium zirconate, boron oxide, zinc oxide, impedance spectroscopy, protonic conductor.

\section{INTRODUÇÃO}

\section{Eletrólitos sólidos}

Eletrólitos sólidos são compostos nos quais ocorre condução iônica em uma faixa de temperatura e de pressão parcial dos elementos que os compõem [1]. Para que um material possa ser usado como eletrólito sólido em dispositivos, deve apresentar uma série de características, sendo a mais importante a alta condutividade iônica $[2,3]$. Outras características desejáveis são impermeabilidade aos gases, condutividade eletrônica desprezível, estabilidade química sob condições específicas, e também boa integridade mecânica $[4,5]$.

O transporte de íons nos eletrólitos sólidos se dá pelo processo de difusão, ou seja, íons (geralmente substitucionais) trocam de posição com defeitos (geralmente vacâncias) da rede cristalina. A mobilidade dos íons é dependente da temperatura e da concentração de defeitos na rede cristalina. Atuando como um isolante eletrônico [3, 6], o eletrólito sólido faz com que a corrente eletrônica não flua internamente, sendo forçada a percorrer um circuito externo, balanceada pela corrente iônica dentro do eletrólito [1]. Os condutores iônicos podem ter como portador de carga íons $\mathrm{O}^{2-}, \mathrm{F}^{-}, \mathrm{Cl}^{-}, \mathrm{Na}^{+}$etc. [7]. Já os eletrólitos que conduzem prótons $\left(\mathrm{H}^{+}\right)$são denominados condutores protônicos. Nos condutores iônicos, a contribuição eletrônica para a condutividade elétrica é insignificante. Os condutores iônicos mais comuns são os de íon oxigênio $\left(\mathrm{O}^{2-}\right)$. Os sólidos condutores protônicos são considerados promissores para a tecnologia do hidrogênio e para a produção de energia limpa [2]. 


\section{Células a combustível}

Os eletrólitos sólidos são utilizados em células a combustível que operam em temperaturas intermediárias $\left(600-800{ }^{\circ} \mathrm{C}\right) \mathrm{e}$ elevadas $\left(>800^{\circ} \mathrm{C}\right)$, conhecidas como células a combustível de óxido sólido (Solid Oxide Fuel Cell - SOFC) [5, 7]. Uma célula a combustível é um dispositivo eletroquímico que transforma a energia química de um combustível em energia elétrica $[8,9]$. Uma célula a combustível unitária é formada por três elementos básicos: o eletrólito condutor de íons, o anodo e o catodo $[4,9]$. O combustível, na forma de gás, é oxidado no anodo e libera elétrons para o circuito externo. Já o oxidante se reduz no catodo, utilizando os elétrons do circuito externo $[9,11]$. No eletrólito ocorre a condução dos íons de um eletrodo para o outro, gerando um fluxo de íons que deve ser equivalente ao fluxo de elétrons através do circuito externo $[9,11]$.

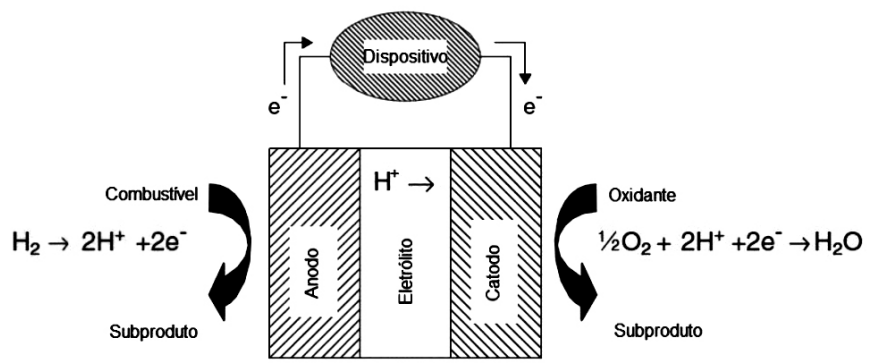

Figura 1: Esquema de funcionamento de uma célula a combustível protônica [4].

[Figure 2: Schematic view of the operation of a protonic solid oxide fuel cell [4].]

\section{Sensores eletroquímicos de oxigênio}

São células galvânicas com eletrólitos sólidos, utilizadas para medidas de teores de oxigênio [12]. Tem ampla utilização no setor industrial, seja no monitoramento de oxigênio em gases de exaustão de canos de escapamento de automóveis ou no monitoramento de oxigênio em processos metalúrgicos [13-15]. Um sensor de oxigênio é geralmente constituído por um eletrólito sólido na forma de tubo fechado em uma extremidade, recoberto interna e externamente por eletrodos metálicos. A parte interna é preenchida com material de potencial de oxigênio conhecido [7]. Quando o sensor é submetido a diferentes teores (potencial químico, atividade ou pressão parcial) de oxigênio, uma força eletromotriz é gerada através do eletrólito, segundo a lei de Nernst-Einstein [1]. A capacidade sensorial é conseqüência da migração de íons de oxigênio provocada por um gradiente de potencial de oxigênio entre as duas superfícies do eletrólito [7].

\section{Condutores protônicos}

Em geral, materiais cerâmicos que apresentam condução protônica são óxidos com estrutura cristalina do tipo perovskita [16-18] dopados com cátions de menor valência [19]. A condução protônica em perovskitas a altas temperaturas foi verificada em 1981 [20]. Quando óxidos com estrutura perovskita, de fórmula geral $\mathrm{ABO}_{3}$, são dopados com cátions de valência menor, estes substituem parcialmente os cátions do sítio B, gerando vacâncias de oxigênio [16]. Defeitos protônicos são formados quando em atmosferas contendo hidrogênio, este reage com as vacâncias para formar íons hidroxila [21]. Supõe-se que as espécies $\mathrm{H}^{+}$ destas hidroxilas sejam as responsáveis pela condução protônica no eletrólito; no entanto, o mecanismo de condução protônica ainda não está esclarecido. $\mathrm{O}$ mais aceito mecanismo de condução protônica é o de Grotthus, no qual a condução protônica está relacionada com a transferência de prótons entre $\mathrm{OH}^{-}$e $\mathrm{O}^{2-}$ adjacentes e a reorientação da hidroxila [22, 23]. Este mecanismo já foi verificado para compostos à base de cerato de bário [22]. Eletrólitos sólidos condutores protônicos são propostos para células a combustível de óxido sólido, pois permitem a redução da temperatura de operação da célula (relativamente às células com eletrólitos sólidos condutores de íons de oxigênio) e também a formação da água, produto da reação final, no catodo, evitando assim a diluição do combustível.

Os óxidos com estrutura perovskita mais comumente utilizados como eletrólitos sólidos para SOFC são aqueles baseados em cerato de bário e zirconato de bário, devido às suas altas condutividades protônicas.

\section{Comparação entre zirconato de bário e cerato de bário}

Zirconato de bário e cerato de bário dopados com ítrio ou gadolínio têm sido muito estudados devido à sua possível aplicação como eletrólito sólido condutor protônico em células a combustível de óxido sólido operacionais em temperaturas intermediárias $(<800$ $\left.{ }^{\circ} \mathrm{C}\right)$. Ambos os materiais apresentam alta condutividade protônica, mas ainda apresentam algumas desvantagens, que são apresentadas a seguir. $\mathrm{O}$ zirconato de bário sinterizado apresenta maior estabilidade química e mecânica e menor valor de condutividade protônica do que o cerato de bário. Cerâmicas de zirconato dopadas, na qual os cátions trivalentes $\mathrm{Y}^{3+}$ ou $\mathrm{Gd}^{3+}$ substituem $\mathrm{Zr}^{4+}$, são condutores protônicos puros em atmosfera de hidrogênio a altas temperaturas $\left(600{ }^{\circ} \mathrm{C}-1000^{\circ} \mathrm{C}\right)[24]$. Entretanto, os valores reportados [25] de condutividade protônica variam em mais de uma ordem de grandeza. A alta resistividade elétrica dos contornos de grão do $\mathrm{BaZrO}_{3}$ não foi compreendida por vários anos, como conseqüência da natureza refratária do material, o que resulta em amostras com grãos pequenos e, portanto, com alta densidade de contornos de grão [24, 26]. Eletrólitos sólidos de cerato de bário sinterizados mostraram ser quimicamente instáveis na presença de $\mathrm{CO}_{2}$, ou em atmosferas contendo $\mathrm{SO}_{2}$ a temperaturas menores que $600{ }^{\circ} \mathrm{C}$, e apresentam baixa resistência mecânica para aplicações práticas [27, 28]. Ao mesmo tempo, a condutividade eletrônica em ceratos de bário é relativamente elevada sob condições redutoras, 
enquanto que é insignificante nos zirconatos de bário [29]. Alguns pesquisadores têm salientado a necessidade de um condutor protônico sólido que combine maior estabilidade química do zirconato e a melhor condutividade elétrica do cerato. Uma solução foi proposta para a gradual substituição do $\mathrm{Zr}^{4+}$ por $\mathrm{Ce}^{4+}$ no zirconato de bário [30-32]. Uma forma importante de melhorar as propriedades elétricas do zirconato de bário seria a redução da resistividade elétrica do contorno de grão [33].

$\mathrm{O}$ condutor protônico zirconato de bário de estrutura perovskita, $\mathrm{BaZrO}_{3}$ dopado com terras raras, tem atraído atenção como um eletrólito para SOFC operacional em temperaturas intermediárias porque apresenta alta estabilidade química em atmosferas contendo $\mathrm{CO}_{2}$ [31], bem como alta condutividade protônica em uma faixa de temperaturas intermediárias $\left(<800{ }^{\circ} \mathrm{C}\right)$ [20]. No entanto, $\mathrm{BaZrO}_{3}$ é difícil de sinterizar [34]. O zirconato de bário de estrutura perovskita é um material refratário com elevado ponto de fusão, baixo coeficiente de expansão térmica, baixa condutividade térmica, boas propriedades mecânicas, estabilidade térmica, e baixa reatividade química com relação a compostos corrosivos [35]. Dopado com cátions trivalentes, é conhecido por absorver prótons na rede cristalina e atuar como condutor protônico em eletrolizadores a vapor, sensores de umidade, bombas de hidrogênio e, particularmente, em SOFCs [4, 35-38]. O zirconato de bário é geralmente obtido por meio de reações de estado sólido em altas temperaturas, utilizando óxidos de bário e de zircônio como materiais de partida, precedidos pela homogeneização dos pós e redução dos tamanhos de partículas. No entanto, essa forma de preparação apresenta vários inconvenientes, como falta de reprodutibilidade do processo, tamanho relativamente grande de partículas, ampla distribuição granulométrica, forte aglomeração e não homogeneidade química. Para superar essas dificuldades de processamento, métodos químicos são cada vez mais importantes na síntese do zirconato de bário. Nestes métodos, o pó é geralmente obtido após uma decomposição de diferentes precursores a baixas temperaturas [39].

A compreensão das propriedades do zirconato de bário foi substancialmente revisada em 1999 [26]. Neste ano, foi reportada a condutividade do zirconato de bário dopado com ítrio como $\sim 5 \times 10^{-5} \mathrm{~S} . \mathrm{cm}^{-1}$ a apenas $140{ }^{\circ} \mathrm{C}$ [26], e este valor foi confirmado em 2000 [24]. Em estudos posteriores, foi notada a baixa reprodutibilidade das medidas de condutividade elétrica do zirconato de bário [40], sendo este fato relacionado com a dificuldade de obter compactos policristalinos homogêneos [25]. Em compactos de zirconato de bário, a contribuição da resistividade do contorno de grão para a resistividade elétrica é alta em temperaturas intermediárias. Em geral, a condutividade do contorno de grão é afetada pelo diâmetro médio do grão, segregação de impurezas e fase secundária nos contornos de grão [34]. Cerâmicas de zirconato de bário foram densificadas por sinterização a alta temperatura $\left(1700{ }^{\circ} \mathrm{C}\right)[24,35]$. No entanto, procura-se reduzir a temperatura de sinterização e otimizar a densificação do compacto final. Métodos para sinterização do $\mathrm{BaZrO}_{3}$ em baixas temperaturas têm sido investigados [41, 42]. Esses materiais foram obtidos com $>93 \%$ da densidade teórica [42] utilizando óxido de zinco ( $\mathrm{ZnO})$ como aditivo de sinterização.

\section{Espectroscopia de impedância}

A espectroscopia de impedância é uma técnica muito utilizada para o estudo dos mecanismos de reações eletroquímicas e para explorar as propriedades de transporte de carga. As medidas de impedância possibilitam a separação das diferentes contribuições dos constituintes do material, quando estes têm diferentes respostas ao campo elétrico aplicado, em um determinado domínio de freqüências. Quando o sistema sob medida possui uma resposta linear, então é possível a associação com elementos de circuito elétrico [43].

A técnica de espectroscopia de impedância consiste em aplicar uma tensão $V(\omega)=V_{0} \exp (j \omega t)$, na qual $j=\sqrt{ }-1$, $\omega$ é a freqüência angular e $V_{0}$ é a amplitude da tensão, e analisar a relação entre tensão $\mathrm{V}(\omega)$ e corrente dada por $\mathrm{I}(\omega)$ = Io exp $\mathrm{j}(\omega \mathrm{t}+\phi)$, na qual $\mathrm{I}_{0}$ é a amplitude da corrente e $\phi$ o ângulo de fase, sendo estes dois parâmetros relacionados pela lei de Ohm V = Z.I [43]. Z representa a impedância. A impedância de um circuito é $Z(\omega)=V / I=Z_{0} \exp (-j \phi)=Z^{\prime}(\omega)$ - i Z” $(\omega)$, na qual $Z$ ' $(\omega)$ e $Z$ ' $(\omega)$ são a parte real e a parte imaginária da impedância, respectivamente, e $Z_{0}=V_{0} / I_{0}$.

Os componentes de um material cerâmico podem geralmente ser tratados, com relação às suas propriedades elétricas, como associações em série de circuitos paralelos entre um resistor e um capacitor $(\mathrm{R} \| \mathrm{C})$. A resistência representa o grau de impedimento da migração de portadores de carga pelos grãos e interfaces, e a capacitância a capacidade de armazenamento de energia nos grãos e interfaces, originária da aplicação do campo elétrico.

Neste artigo, a densificação e a condutividade elétrica em diferentes atmosferas do composto $\mathrm{BaZr}_{0,8} \mathrm{Y}_{0,2} \mathrm{O}_{3-\delta}$ foram investigadas utilizando óxidos de boro e de zinco como aditivos de sinterização. $\mathrm{O}$ óxido de boro tem ponto de fusão $\sim 515{ }^{\circ} \mathrm{C}$ e de sublimação $\sim 1500{ }^{\circ} \mathrm{C}$, podendo conseqüentemente formar fase líquida durante a sinterização e ser eliminado no patamar de sinterização. O óxido de zinco se distribui na região intergranular promovendo crescimento de grão e densidade $>93 \%$ da densidade teórica a temperaturas reduzidas [42].

\section{EXPERIMENTAL}

Foram preparados, por mistura de óxidos, três grupos de $\mathrm{BaZr}_{0,8} \mathrm{Y}_{0,2} \mathrm{O}_{3-\delta}$ partindo de teores estequiométricos dos óxidos de bário, de zircônio e de ítrio. Foram calculadas as massas desses óxidos, pesadas em balança eletrônica Mettler Toledo AB204, e homogeneizadas em almofariz de ágata durante $10 \mathrm{~min}$. Além da homogeneização manual, foi feita uma cominuição em moinho atritor, contendo 60 $\mathrm{mL}$ de esferas de zircônia-ítria tetragonal (3Y-TZP, Tosoh, Japão) de diâmetro $2 \mathrm{~mm}$ e $30 \mathrm{~mL}$ de álcool isopropílico, 
agitados por 15 min a $500 \mathrm{rpm}$. Após evaporação do álcool isopropílico, o pó cerâmico foi tratado termicamente a $1500{ }^{\circ} \mathrm{C}$ por $4 \mathrm{~h}$. Esse ciclo de homogeneização (manual ou no moinho atritor) e tratamento térmico foi repetido 2 vezes para permitir completar a reação de formação de fase, que se processa por difusão.

Os pós cerâmicos foram caracterizados quanto ao teor de fases cristalinas por difração de raios $\mathrm{X}$ na faixa de $2 \theta$ de $20^{\circ}$ a $80^{\circ}$, com passo $0,05^{\circ}$ e tempo por passo 5 $\mathrm{s}$, com radiação Cuka, em um difratômetro Bruker-AXS D8 Advance. Para a indexação das fases cristalinas foram utilizados os arquivos JCPDS.

A análise de distribuição de tamanho de partículas, por espalhamento laser, dos pós cerâmicos de $\mathrm{BaZr}_{0,8} \mathrm{Y}_{0,2} \mathrm{O}_{3-\delta} \mathrm{com}$ 2 peso $\% \mathrm{~B}_{2} \mathrm{O}_{3}$ e 2 peso $\% \mathrm{ZnO}$, preparados por mistura de óxidos, foi feita com uma amostragem de aproximadamente $1 \mathrm{~g}$ à temperatura ambiente, sendo dispersos em água com pirofosfato de sódio e a dispersão feita em ultra-som durante 5 min. O equipamento utilizado foi o granulômetro Cilas 1064.

As análises termogravimétrica e térmica diferencial dos pós cerâmicos $\mathrm{BaZr}_{0,8} \mathrm{Y}_{0,2} \mathrm{O}_{3-\delta}$ com 2 peso $\% \mathrm{~B}_{2} \mathrm{O}_{3}$ e 2 peso\% $\mathrm{ZnO}$ foram feitas com taxa de aquecimento e resfriamento de $10^{\circ} \mathrm{C} / \mathrm{min}$ até $1550^{\circ} \mathrm{C}$ sob atmosfera de ar sintético, tendo como material de referência alumina alfa. O equipamento usado foi Netzsch modelo STA 409E.

Após a incorporação dos aditivos, os pós cerâmicos foram compactados uniaxialmente em prensa hidráulica, em matriz metálica de punções de diâmetro $12 \mathrm{~mm}$, com carga de $\sim 600$ kgf. Os corpos cerâmicos a verde com e sem aditivos foram sinterizados com taxa de aquecimento $2{ }^{\circ} \mathrm{C} /$ min, patamares de $1 \mathrm{~h} \mathrm{em} 500{ }^{\circ} \mathrm{C} \mathrm{e} 4 \mathrm{~h} \mathrm{em} 1500{ }^{\circ} \mathrm{C}$, e taxas de resfriamento de $5{ }^{\circ} \mathrm{C} / \mathrm{min}$ até $1000^{\circ} \mathrm{C}$ e de $10^{\circ} \mathrm{C} / \mathrm{min}$ até temperatura ambiente, para minimizar o choque térmico.

Foram feitas medidas para determinar a densidade a verde, geométrica e pela técnica de Arquimedes das amostras sinterizadas. Para a técnica de Arquimedes foi usado querosene como meio líquido [44] e balança analítica Mettler H315.

Os compactos cerâmicos foram caracterizados quanto ao teor de fases cristalinas por difração de raios X.

Medidas de espectroscopia de impedância foram feitas na faixa de freqüência de $40 \mathrm{~Hz}$ a $110 \mathrm{MHz}$, em temperaturas entre $400{ }^{\circ} \mathrm{C}$ e $600{ }^{\circ} \mathrm{C}$ em um analisador de impedância Agilent 4294A, sob diferentes atmosferas: ar, argônio seco e argônio úmido. A temperatura das amostras foi monitorada com um termopar tipo $\mathrm{S}$ conectado a um multímetro digital Fluke 8050A.

\section{RESULTADOS E DISCUSSÃO}

A caracterização dos pós foi feita por difração de raios $\mathrm{X}$. As amostras preparadas por mistura de óxidos foram submetidas a três tratamentos térmicos a $1500{ }^{\circ} \mathrm{C}$ por $4 \mathrm{~h}$, com moagens intermediárias, até atingir majoritariamente a fase desejada, perovskita cúbica (JCPDS 6-399).

A Fig. 2 mostra os difratogramas de raios $\mathrm{X}$ dos pós de

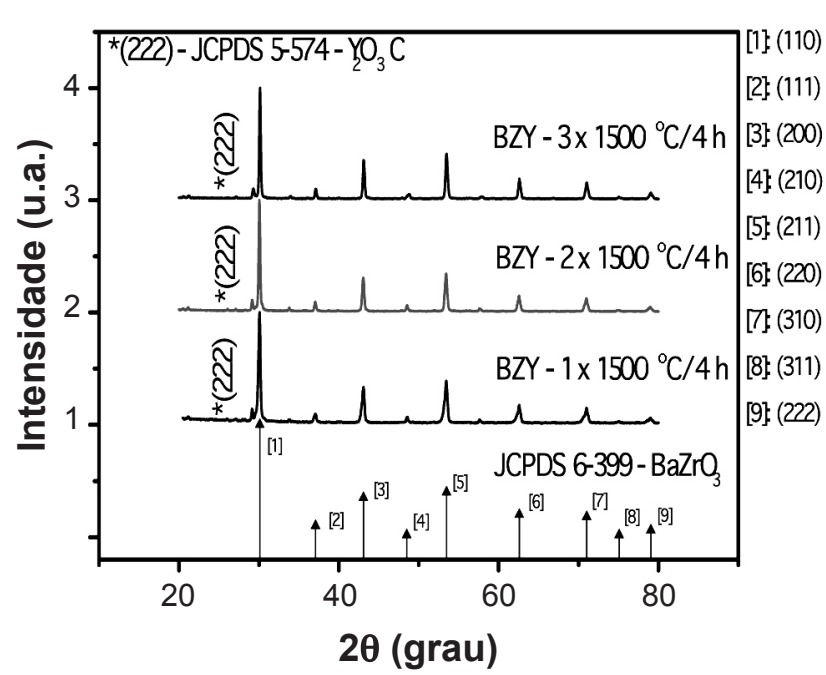

Figura 2: Difratogramas de raios $\mathrm{X}$ dos pós cerâmicos de $\mathrm{BaZr}_{0,8} \mathrm{Y}_{0,2} \mathrm{O}_{3-\delta}$ preparados por mistura de óxidos de zircônio, de ítrio e de bário, e raias de difração do $\mathrm{BaZrO}_{3}$ (JCPDS 6-399).

[Figure 2: X-ray diffraction patterns of $\mathrm{BaZr}_{0.8} \mathrm{Y}_{0.2} \mathrm{O}_{3-\delta}$ ceramic powders prepared by the mixing oxide technique, and the reflections of $\mathrm{BaZrO}_{3}$ (JCPDS 6-399).]

$\mathrm{BaZr}_{0,8} \mathrm{Y}_{0,2} \mathrm{O}_{3-\delta}$ (BZY) homogeneizados manualmente em almofariz de ágata.

Os difratogramas mostram a formação da fase perovskita cúbica característica do composto $\mathrm{BaZr}_{0,8} \mathrm{Y}_{0,2} \mathrm{O}_{3-\delta}$. Apresenta também um pico não relacionado com a estrutura do $\mathrm{BaZrO}_{3}$, *(222), que representa uma fase provavelmente relacionada com o acúmulo de ítria provocada pela volatilização do óxido de bário. O pico principal do $\mathrm{Y}_{2} \mathrm{O}_{3}$ em $2 \theta=29,1^{\circ}$ e os demais proeminentes $\left(46 \%\right.$ em $2 \theta=48,54^{\circ}$ e $31 \%$ em $2 \theta=57,59^{\circ}$ ) coincidem com os da perovskita cúbica do $\mathrm{BaZrO}_{3}$. Resultado similar foi obtido para os pós cerâmicos após moagem em moinho atritor.

Os resultados de difração de raios $\mathrm{X}$ dos pós de zirconato de bário dopado com ítrio mostram que os materiais preparados por meio da técnica de mistura de óxidos apresentam majoritariamente a fase perovskita cúbica, característica do condutor protônico.

As Figs. 3 e 4 mostram a distribuição de tamanho de partículas do composto $\mathrm{BaZr}_{0,8} \mathrm{Y}_{0,2} \mathrm{O}_{3-\delta}$ preparado pela técnica de mistura de óxidos com homogeneização manual em almofariz de ágata e após moagem em moinho atritor, respectivamente.

A distribuição na Fig. 3 é centralizada majoritariamente em $\sim 0,2 \mu \mathrm{m}$ e $\sim 33 \mu \mathrm{m}$ e o diâmetro médio (maior parte das partículas) é $\sim 13 \mu \mathrm{m}$.

A distribuição é centralizada em $\sim 0,2 \mu \mathrm{m}$ e $\sim 28 \mu \mathrm{m}$ e o diâmetro médio aferido é $\sim 10 \mu \mathrm{m}$, menor do que do pó preparado sem moagem. No experimento realizado, o pó submetido à cominuição em moinho atritor apresentou, como esperado, um tamanho de partícula menor quando comparado ao pó homogeneizado manualmente em almofariz de ágata.

A Fig. 5 mostra os resultados das análises termogravimétrica e térmica diferencial dos materiais 


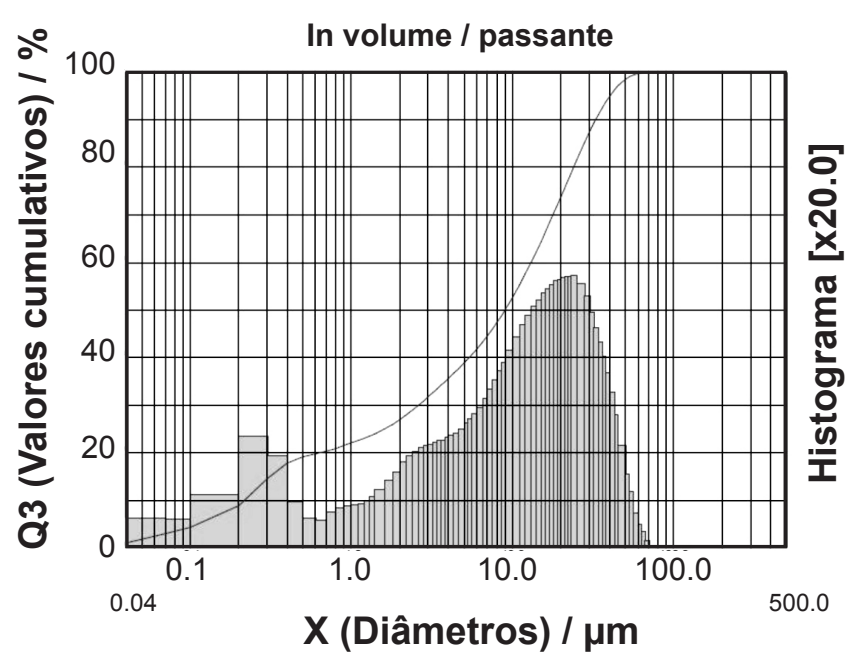

Figura 3: Distribuição de tamanho de partícula do $\mathrm{BaZr}_{0,8} \mathrm{Y}_{0,2} \mathrm{O}_{3-\delta}$ preparado pela técnica de mistura de óxidos.

[Figure 3: Distribution of particle size of $\mathrm{BaZr} r_{0.8} Y_{0.2} \mathrm{O}_{3-\delta}$ prepared by the mixing of oxides technique.]

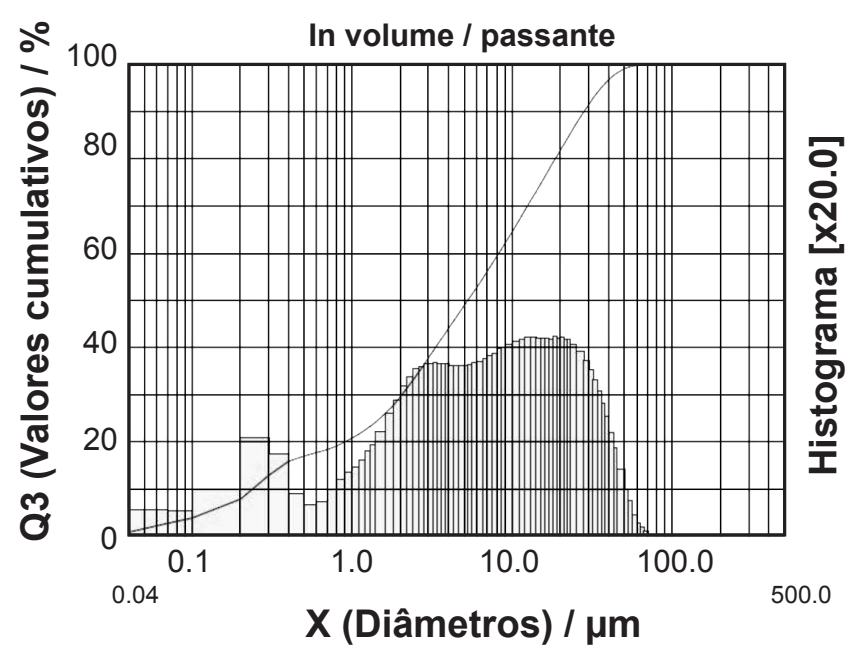

Figura 4: Distribuição do tamanho de partículas de $\mathrm{BaZr}_{0,8} \mathrm{Y}_{0,2} \mathrm{O}_{3-\delta}$ preparado por mistura de óxidos e submetido a moagem em moinho atritor.

[Figure 4: Distribution of particle size of $\mathrm{BaZr}_{0.8} \mathrm{Y}_{0.2} \mathrm{O}_{3-\delta}$ prepared by the mixing of oxides technique, after comminuting in an attritor.]

usados para preparar o composto $\mathrm{BaZr}_{0,8} \mathrm{Y}_{0,2} \mathrm{O}_{3-\delta}$ por mistura de zircônia, ítria e óxido de bário.

Há uma perda de $\sim 17 \%$ da massa total dividida em três faixas de temperatura. A primeira, da temperatura ambiente até aproximadamente $200{ }^{\circ} \mathrm{C}$ é atribuída à perda de água adsorvida e à decomposição do hidróxido de bário proveniente da adsorção de água no óxido de bário [45].

O pico endotérmico em $\sim 130^{\circ} \mathrm{C}$ é devido à decomposição do hidróxido de bário por causa da reação que ocorre na temperatura ambiente com a umidade. $\mathrm{O}$ pico exotérmico em aproximadamente $370{ }^{\circ} \mathrm{C}$ é provavelmente resultado da reação do hidróxido de bário anidro com oxigênio formando peróxido de bário. Entre aproximadamente $600^{\circ} \mathrm{Ce} 800^{\circ} \mathrm{C}$ há uma perda de massa atribuída à decomposição do carbonato de bário. Finalmente entre $\sim 1000{ }^{\circ} \mathrm{C}$ e $\sim 1300{ }^{\circ} \mathrm{C}$ também

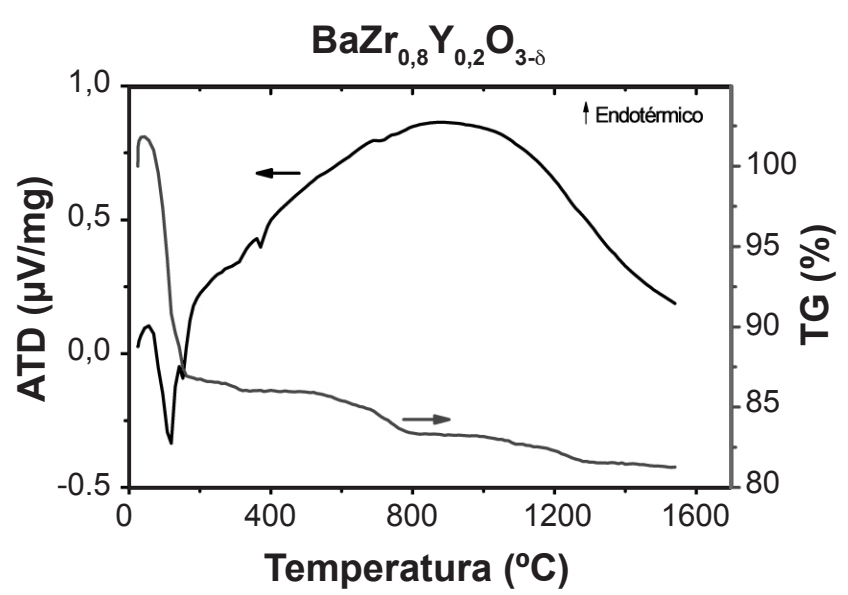

Figura 5: Curvas termogravimétrica (TG) e térmica diferencial (ATD) da mistura $\mathrm{BaO}+\mathrm{ZrO}_{2}+\mathrm{Y}_{2} \mathrm{O}_{3}$ para formação do composto $\mathrm{BaZr}_{0,8} \mathrm{Y}_{0,2} \mathrm{O}_{3-\delta}$.

[Figure 5: Thermogravimetric and differential thermal analysis curves of the $\mathrm{BaO}+\mathrm{ZrO}_{2}+\mathrm{Y}_{2} \mathrm{O}_{3}$ mixture for preparing the $\mathrm{BaZr}_{0.8} \mathrm{Y}_{0.2} \mathrm{O}_{3-\delta}$ compound.]

houve perda de massa por causa da evaporação do óxido de bário, e relacionada com a transformação de fase do material. Estes resultados mostram que a reação para a formação do composto $\mathrm{BaZr}_{0,8} \mathrm{Y}_{0,2} \mathrm{O}_{2,9}$ se completa na faixa entre a temperatura ambiente e aproximadamente $1200^{\circ} \mathrm{C}$.

Foram preparadas composições de $\mathrm{BaZr}_{0,8} \mathrm{Y}_{0,2} \mathrm{O}_{2,9}$ com e sem aditivos de sinterização, o óxido de zinco e o óxido de boro. Inicialmente foram misturados os óxidos $\mathrm{BaO}, \mathrm{ZrO}_{2} \mathrm{e}$ $\mathrm{Y}_{2} \mathrm{O}_{3}$ e homogeneizados por moagem em moinho atritor. A mistura de pós foi submetida a três tratamentos térmicos de $1500{ }^{\circ} \mathrm{C} / 4 \mathrm{~h}$ com taxas de aquecimento e resfriamento de $10{ }^{\circ} \mathrm{C} / \mathrm{min}$. Em seguida, foram adicionados os aditivos nas proporções de 1,2 e 5 peso\%, e foi feita a compactação. Os corpos compactados foram submetidos à sinterização e avaliados quanto à densidade. A Tabela I mostra os valores

Tabela I - Densidades geométrica $\rho_{\mathrm{g}}$ e obtida pela técnica de Arquimedes $\rho_{\mathrm{A}}$ dos compactos cerẩmicos de $\mathrm{BaZr}_{0,8} \mathrm{Y}_{0,2} \mathrm{O}_{3-\delta}$ sinterizados a $1500^{\circ} \mathrm{C}$ por $4 \mathrm{~h}$.

[Table I - Geometric and Archimedes densities of the BaZr $r_{0.8} Y_{0.2} O_{3-\delta}$ sintered at $\left.1500^{\circ} \mathrm{C} / 4 \mathrm{~h}.\right]$

\begin{tabular}{lcccc}
\hline Composição & $\begin{array}{c}\rho_{\mathrm{g}} \\
\left(\mathrm{g} / \mathrm{cm}^{3}\right)\end{array}$ & $\% \mathrm{DT}^{*}$ & $\begin{array}{c}\rho_{\mathrm{A}} \\
\left(\mathrm{g} / \mathrm{cm}^{3}\right)\end{array}$ & $\% \mathrm{DT}^{*}$ \\
\hline $\mathrm{BZY}$ & 3,56 & 57,3 & 5,35 & 86,1 \\
$\mathrm{BZY}+1$ peso\% $\mathrm{B}_{2} \mathrm{O}_{3}$ & 3,61 & 58,1 & 5,37 & 86,5 \\
$\mathrm{BZY}+2$ peso\% $\mathrm{B}_{2} \mathrm{O}_{3}$ & 3,92 & 63,1 & 5,35 & 86,1 \\
$\mathrm{BZY}+5$ peso\% $\mathrm{B}_{2} \mathrm{O}_{3}$ & 4,51 & 72,6 & 5,11 & 82,3 \\
& & & & \\
$\mathrm{BZY}+1$ peso\% ZnO & 3,63 & 58,4 & 5,87 & 94,5 \\
$\mathrm{BZY}+2$ peso\% ZnO & 3,98 & 64,1 & 5,89 & 94,8 \\
$\mathrm{BZY}+5$ peso\% ZnO & 4,54 & 73,1 & 5,89 & 94,8 \\
\hline
\end{tabular}

* densidade teórica: $6,21 \mathrm{~g} / \mathrm{cm}^{3}$. 
de densidade geométrica e a determinada pela técnica de Arquimedes.

Adensidade teórica foi determinada por meio da avaliação dos parâmetros de rede da célula unitária pela técnica de difração de raios $\mathrm{X}$ e pelas massas dos átomos que compõem a célula unitária. $O$ valor determinado foi $6,21 \mathrm{~g} / \mathrm{cm}^{3}$. A densidade geométrica aumentou com a adição de óxido de boro, passando de $\sim 58 \%$ para $\sim 73 \%$ da densidade teórica. O zirconato de bário dopado com ítrio obteve uma densidade de $\sim 87 \%$ da densidade teórica quando foi adicionado $1 \%$ de óxido de boro, aproximadamente a mesma densidade do material sem óxido de boro. Conseqüentemente, o procedimento experimental seguido não foi eficiente para melhorar a densificação. $\mathrm{O}$ aumento da densidade com a adição de óxido de zinco foi relevante, passando de $\sim 58$ para $\sim 73 \%$ da densidade teórica. Já a densidade obtida pela técnica de Arquimedes mostra uma densificação de $~ 95 \%$ da densidade teórica.

As análises por difração de raios $\mathrm{X}$ permitiram a avaliação dos valores de parâmetro de rede dos zirconatos de bário dopados com ítrio sem e com adição de óxido de boro e de óxido de zinco. Os resultados da determinação dos parâmetros de rede mostram que a solubilidade do óxido de zinco a $1500{ }^{\circ} \mathrm{C}$ no zirconato de bário está entre 2 e $5 \%$. Com $5 \%$ o composto já é bifásico provavelmente com segregação de $\mathrm{ZnO}$ nos contornos de grão. Já o óxido de boro começa a solubilizar no zirconato de bário a $1500{ }^{\circ} \mathrm{C}$ a partir da adição de teores acima de $2 \%$. A introdução de $\mathrm{Zn}^{2+}$ na rede do zirconato de bário já tinha sido reportada [46]. Como o objetivo do uso de aditivo de sinterização é o da densificação do condutor protônico zirconato de bário sem a deterioração de sua condutividade elétrica, $2 \%$ de óxido de boro pode ser estabelecido como o limite de teor deste aditivo.

A Fig. 6 mostra os difratogramas de raios $\mathrm{X}$ da composição $\mathrm{BaZr}_{0,8} \mathrm{Y}_{0,2} \mathrm{O}_{3-\delta}$ com e sem óxido de boro, nas proporções de 1,2 e 5 peso $\%$, juntamente com as principais raias do composto $\mathrm{BaZrO}_{3}$, JCPDS 6-399.

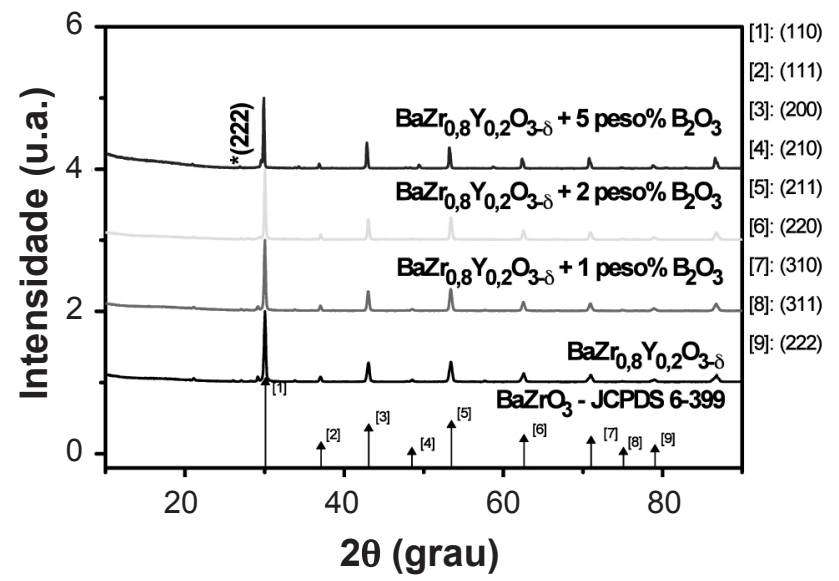

Figura 6: Difratogramas de raios $\mathrm{X}$ dos compactos cerâmicos sinterizados de $\mathrm{BaZr}_{0,8} \mathrm{Y}_{0,2} \mathrm{O}_{3-\delta}$ com e sem $\mathrm{B}_{2} \mathrm{O}_{3}$, e raias de difração do $\mathrm{BaZrO}_{3}$ (JCPDS 6-399).

[Figure 6: X-ray diffraction patterns of sintered $\mathrm{BaZr}_{0.8} \mathrm{Y}_{0.2} \mathrm{O}_{3-\delta}$ pellets with and without $\mathrm{B}_{2} \mathrm{O}_{3}$, and the reflections of $\mathrm{BaZrO}_{3}$ (JCPDS 6-399).]
Os difratogramas mostram a formação da fase perovskita cúbica característica do composto $\mathrm{BaZr}_{0,8} \mathrm{Y}_{0,2} \mathrm{O}_{2,9}$. Como no caso dos pós, apresentam um pico relacionado com a ítria cúbica (JCPDS 5-574), devido provavelmente ao acúmulo de ítria pela volatilização do óxido de bário [41]. Trata-se de um caso típico de desestabilização do composto, promovida pela presença reativa do óxido de boro líquido nos contornos de grão do zirconato de bário.

A Fig. 7 mostra os difratogramas de raios $\mathrm{X}$ da composição $\mathrm{BaZr}_{0,8} \mathrm{Y}_{0,2} \mathrm{O}_{3-\delta}$ com e sem óxido de zinco, nas proporções de 1,2 e 5 peso $\%$, juntamente com as principais raias do composto $\mathrm{BaZrO}_{3}$, JCPDS 6-399.

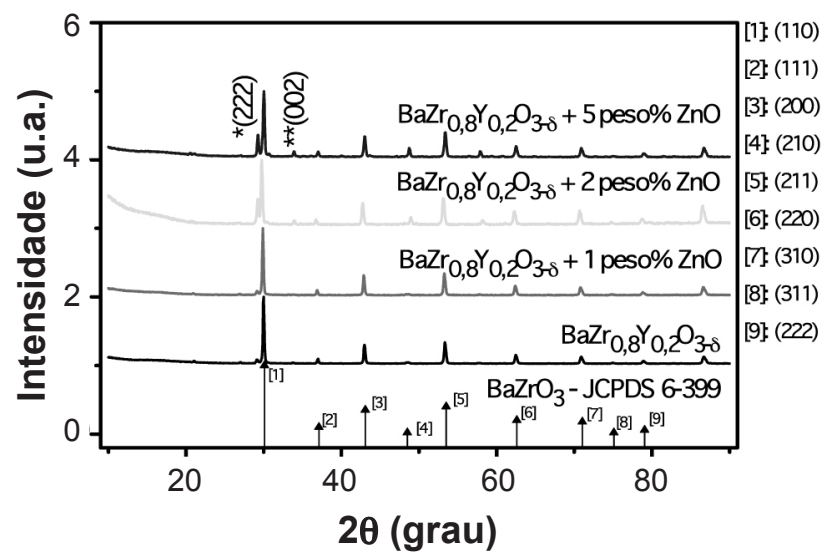

Figura 7: Difratogramas de raios $\mathrm{X}$ dos compactos cerâmicos de $\mathrm{BaZr}_{0.8} \mathrm{Y}_{0,2} \mathrm{O}_{3-\delta}$ com e sem $\mathrm{ZnO}$, e raias de difração do $\mathrm{BaZrO}_{3}$ (JCPDS 6-399).

[Figure 7: X-ray diffraction patterns of $\mathrm{BaZr}_{0.8} Y_{0.2} \mathrm{O}_{3-\delta}$ pellets sintered with and without $\mathrm{ZnO}$, and reflections of $\mathrm{BaZrO}{ }_{3}$ (JCPDS 6-399).]

Os difratogramas mostram a fase perovskita cúbica característica do composto $\mathrm{BaZr}_{0,8} \mathrm{Y}_{0,2} \mathrm{O}_{3-\delta}$ e três picos extras: *(222), provavelmente devido a ítria cúbica (JCPDS 5-574), **(002) devido ao óxido de zircônio de estrutura tetragonal (JCPDS 42-1164); e ***(131) devido ao óxido de zircônio de estrutura monoclínica (JCPDS 88-2390). A presença de fases devidas a reações do óxido de zinco com o zirconato de bário já foi reportada [47].

A análise do comportamento elétrico é importante para avaliar o efeito da presença de aditivos de sinterização, quer na formação de novas fases estruturais quer na sua segregação nos contornos de grão. Novas fases estruturais podem comprometer a condutividade protônica intragranular enquanto que segregação nos contornos de grão pode comprometer a condutividade intergranular. A primeira é mais importante porque a segunda deve ser desprezível na temperatura de operação de uma célula a combustível $\left(>600^{\circ} \mathrm{C}\right)$.

A Fig. 8 mostra os diagramas de impedância de zirconato de bário com e sem $\mathrm{B}_{2} \mathrm{O}_{3}$, sinterizados a $1500{ }^{\circ} \mathrm{C}$ e medidos a $600{ }^{\circ} \mathrm{C}$, sob atmosfera ambiente.

Os menores valores de resistividade elétrica foram obtidos com $1 \%$ e $2 \%$ em peso de $\mathrm{B}_{2} \mathrm{O}_{3}$. Os valores de resistividade elétrica foram $\sim 345 \mathrm{kOhm} . \mathrm{cm}, \sim 44 \mathrm{kOhm} . \mathrm{cm}$ 
e $\sim 34$ kOhm.cm para $\mathrm{BaZr}_{0,8} \mathrm{Y}_{0,2} \mathrm{O}_{3-\delta}$ sem e com 1\% $\mathrm{B}_{2} \mathrm{O}_{3}$ e $2 \% \mathrm{~B}_{2} \mathrm{O}_{3}$, respectivamente. Compostos de $\mathrm{BaZr}_{0,8} \mathrm{Y}_{0,2} \mathrm{O}_{3-\delta}$ com $5 \% \quad \mathrm{~B}_{2} \mathrm{O}_{3}$ apresentaram um grande aumento na resistividade elétrica relativamente ao composto sem adição de $\mathrm{B}_{2} \mathrm{O}_{3}$ provavelmente por formação de segunda fase nos contornos de grão, em acordo com os resultados de difração de raios $\mathrm{X}$.

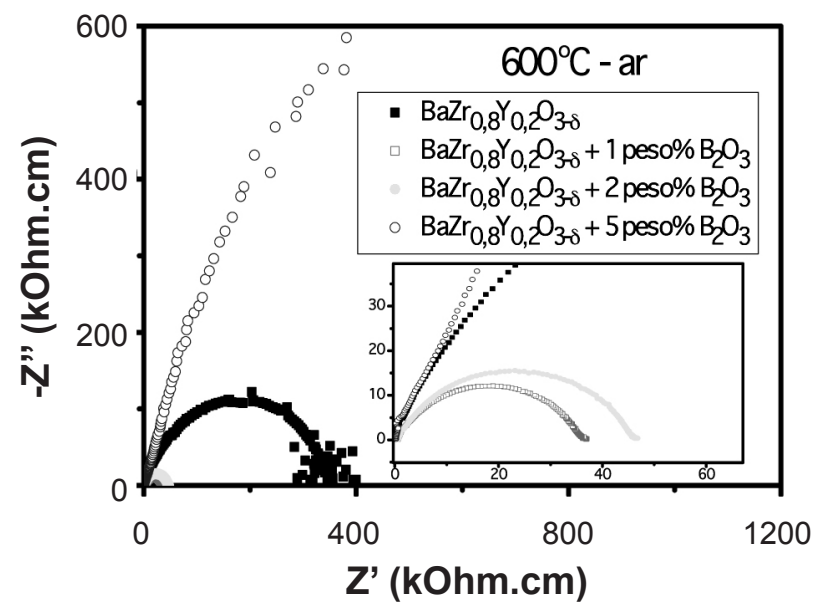

Figura 8: Diagramas de impedância de $\mathrm{BaZr}_{0,8} \mathrm{Y}_{0,2} \mathrm{O}_{3-\delta}$ com e sem $\mathrm{B}_{2} \mathrm{O}_{3}$ medidos a $600{ }^{\circ} \mathrm{C}$. Inserido um gráfico na região de altas freqüências.

[Figure 8: Impedance diagrams of $\mathrm{BaZr}_{0.8} \mathrm{Y}_{0.2} \mathrm{O}_{3-8}$ with and without $\mathrm{B}_{2} \mathrm{O}_{3}$ measured at $600^{\circ} \mathrm{C}$. Inset: zoom in the high frequency region.]

A Fig. 9 mostra os diagramas de impedância de zirconato de bário com e sem $\mathrm{B}_{2} \mathrm{O}_{3}$, sinterizados a $1500{ }^{\circ} \mathrm{C}$ e medidos a $600{ }^{\circ} \mathrm{C}$, sob atmosfera de argônio seco. O objetivo destes experimentos foi o de reduzir o teor de oxigênio e o teor de umidade na câmara de medidas, evitando assim a probabilidade de absorção de espécies químicas formadoras de portadores de carga para o transporte elétrico (vapor

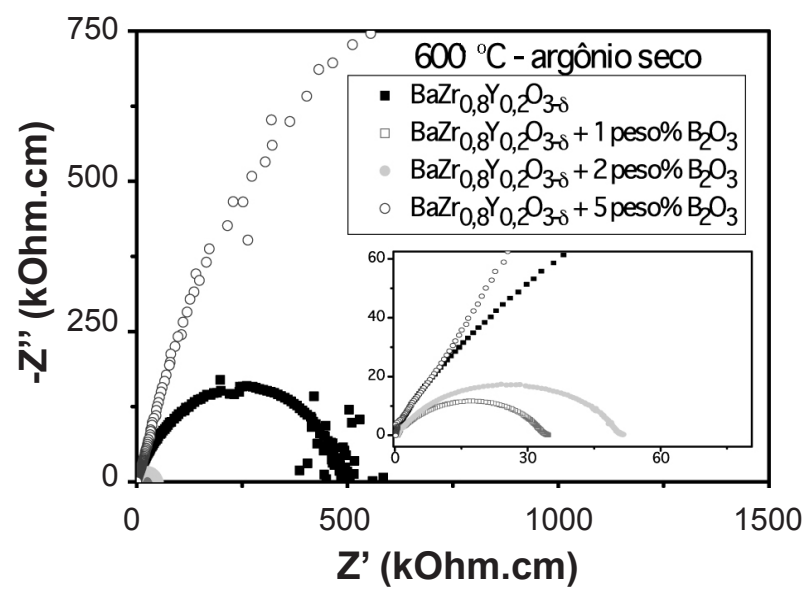

Figura 9: Diagramas de impedância de $\mathrm{BaZr}_{0,8} \mathrm{Y}_{0,2} \mathrm{O}_{3-\delta}$ com e sem $\mathrm{B}_{2} \mathrm{O}_{3}$ em diferentes proporções, medidos a $600^{\circ} \mathrm{C}$, sob atmosfera de argônio seco. Inserido um gráfico na região de altas freqüências. [Figure 9: Impedance diagrams of $\mathrm{BaZr}_{0.8} \mathrm{Y}_{0.2} \mathrm{O}_{3-8}$ with and without $\mathrm{B}_{2} \mathrm{O}_{3}$, measured at $600{ }^{\circ} \mathrm{C}$, unde dry argon. Inset: high frequency region.] d'água que forneceria hidrogênio para o transporte de prótons e oxigênio que poderia produzir íons de oxigênio para o transporte iônico).

Os resultados são semelhantes aos obtidos ao ar (Fig. 8). Entretanto, os valores de resistividade elétrica a $600{ }^{\circ} \mathrm{C}$ para os compostos de zirconato de bário sem e com $1 \%$ e $2 \%$ de óxido de boro são $500 \mathrm{kOhm} . \mathrm{cm}, 50 \mathrm{kOhm} . \mathrm{cm}$ e $33 \mathrm{kOhm} . \mathrm{cm}$, respectivamente. Somente o composto sem aditivos apresentou valores de resistividade diferentes (345 kOhm.cm para $500 \mathrm{kOhm} . \mathrm{cm}$ sob ar e argônio, respectivamente), provavelmente porque os compostos sem aditivo apresentam mais porosidade aberta, facilitando a reação com o gás da atmosfera da câmara de medida. Assim, um dos papéis mais importantes do óxido de boro como aditivo seria o de preencher (eliminar parcialmente) os poros, facilitando a aproximação dos grãos.

A Fig. 10 mostra os diagramas de impedância de zirconato de bário com e sem $\mathrm{B}_{2} \mathrm{O}_{3}$, sinterizados a $1500{ }^{\circ} \mathrm{C}$ e medidos a $600{ }^{\circ} \mathrm{C}$, sob atmosfera de argônio úmido.

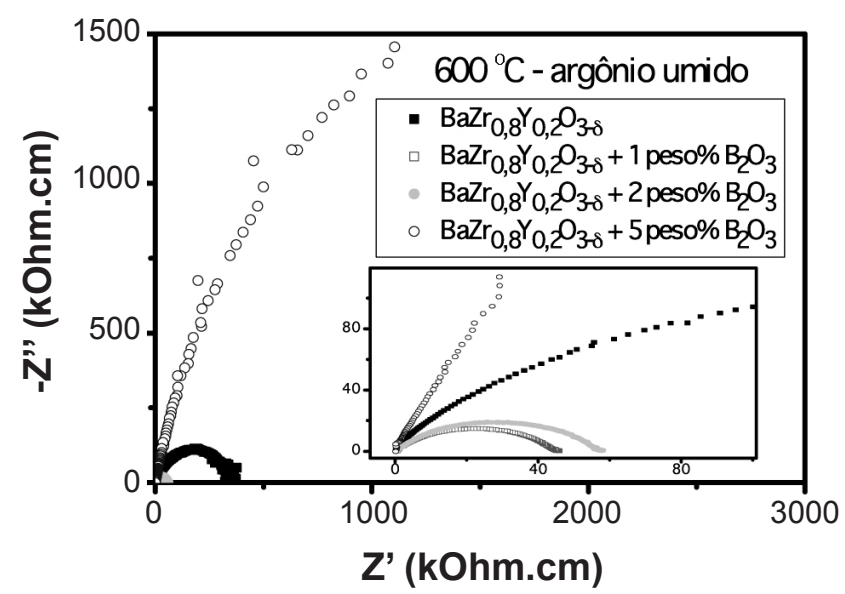

Figura 10: Diagramas de impedância de $\mathrm{BaZr}_{0,8} \mathrm{Y}_{0,2} \mathrm{O}_{3-\delta}$ com e sem $\mathrm{B}_{2} \mathrm{O}_{3}$, medidos a $600{ }^{\circ} \mathrm{C}$ sob atmosfera de argônio úmido. Inserido um gráfico na região de altas freqüências.

[Figure 10: Impedance diagrams of $\mathrm{BaZr}_{0.8} \mathrm{Y}_{0.2} \mathrm{O}_{3-\delta}$ with and without $\mathrm{B}_{2} \mathrm{O}_{3}$, measured at $600{ }^{\circ} \mathrm{C}$ under humid argon. Inset: high frequency region.]

Os resultados são semelhantes aos obtidos anteriormente ao ar (Fig. 8) e sob atmosfera de argônio (Fig. 9). Os valores de resistividade elétrica foram determinados: $345 \mathrm{kOhm} . \mathrm{cm}$, $57 \mathrm{kOhm} . \mathrm{cm}$ e $44 \mathrm{kOhm} . \mathrm{cm}$ para os compostos sem, com $2 \%$ e com $1 \%$ de óxido de boro.

Esses resultados são sumarizados na Tabela II.

A seguir serão apresentados os resultados de medidas de espectroscopia de impedância de corpos sinterizados de $\mathrm{BaZr}_{0,8} \mathrm{Y}_{0,2} \mathrm{O}_{3-\delta}$ sem e com adição de $\mathrm{ZnO}$.

A Fig. 11 mostra os diagramas de impedância de zirconato de bário com e sem $\mathrm{ZnO}$, sinterizados a $1500{ }^{\circ} \mathrm{C}$ e medidos a $600{ }^{\circ} \mathrm{C}$ ao ar.

É evidente o efeito benéfico da adição de óxido de zinco durante a sinterização do zirconato de bário dopado com ítrio. A resistividade elétrica a $600{ }^{\circ} \mathrm{C}$ diminui pela metade com a incorporação de $1 \%$ de óxido de zinco. Há uma maior 
Tabela II - Valores de resistividade elétrica (Ohm.cm) de $\mathrm{BaZr}_{0,8} \mathrm{Y}_{0,2} \mathrm{O}_{3-\delta}$ sem e com adição de $1 \%$ e $2 \%$ de $\mathrm{B}_{2} \mathrm{O}_{3}$ sob diferentes atmosferas.

[Table II - Values of electrical resistivity (Ohm.cm) of $\mathrm{BaZr}_{0.8} \mathrm{Y}_{0.2} \mathrm{O}_{3-8}$ without and with $1 \%$ and $2 \%$ of $\mathrm{B}_{2} \mathrm{O}_{3}$ addition under different atmospheres.]

\begin{tabular}{cccc}
\hline & $\mathrm{BaZr}_{0,8} \mathrm{Y}_{0,2} \mathrm{O}_{3-\delta}$ & $\mathrm{BaZr}_{0,8} \mathrm{Y}_{0,2} \mathrm{O}_{3-\delta}+1 \% \mathrm{~B}_{2} \mathrm{O}_{3}$ & $\mathrm{BaZr}_{0,8} \mathrm{Y}_{0,2} \mathrm{O}_{3-\delta}+2 \% \mathrm{~B}_{2} \mathrm{O}_{3}$ \\
\hline Ar & 345 & 44 & 34 \\
Argônio seco & 500 & 50 & 57 \\
Argônio úmido & 345 & 33 & 44 \\
\hline
\end{tabular}

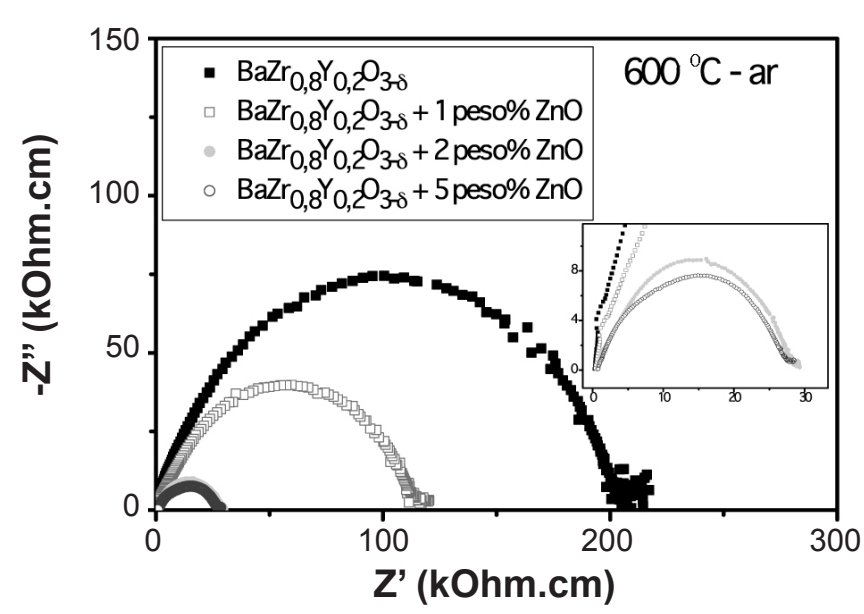

Figura 11: Diagramas de impedância de $\mathrm{BaZr}_{0,8} \mathrm{Y}_{0,2} \mathrm{O}_{3-\delta}$ com e sem $\mathrm{ZnO}$, medidos a $600{ }^{\circ} \mathrm{C}$ ao ar. Inserido um gráfico na região de altas freqüências.

[Figure 11: Impedance diagrams of $\mathrm{BaZr}_{0.8} \mathrm{Y}_{0.2} \mathrm{O}_{3-\delta}$ with and without $\mathrm{ZnO}$, measured at $600{ }^{\circ} \mathrm{C}$ in air. Inset: high frequency region.]

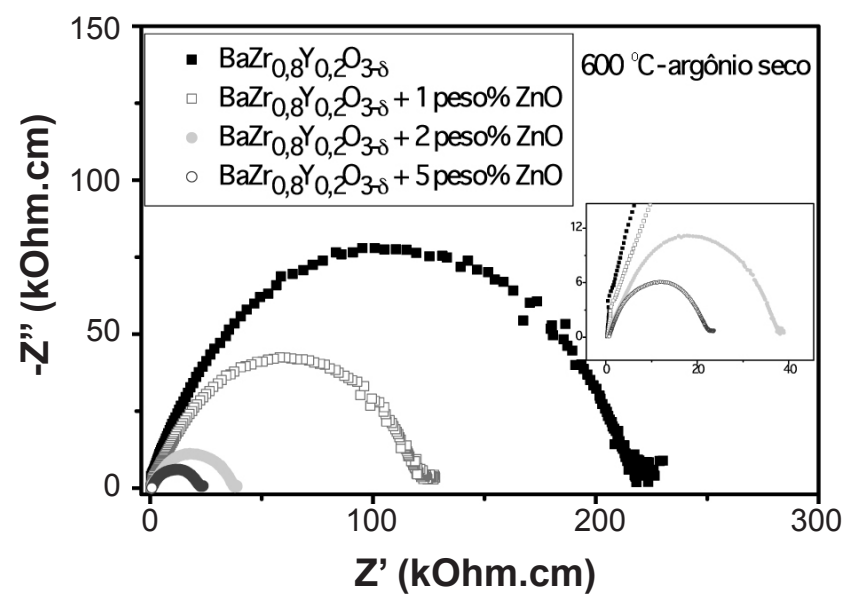

Figura 12: Diagramas de impedância de $\mathrm{BaZr}_{0,8} \mathrm{Y}_{0,2} \mathrm{O}_{3-\delta}$ com e sem $\mathrm{ZnO}$, medidos a $600{ }^{\circ} \mathrm{C}$ sob atmosfera de argônio seco. Inserido um gráfico na região de altas freqüências.

[Figure 12: Impedance diagrams of $\mathrm{BaZr}_{0.8} \mathrm{Y}_{0.2} \mathrm{O}_{3-\delta}$ with and without $\mathrm{ZnO}$, measured at $600{ }^{\circ} \mathrm{C}$ under dry argon. Inset: high frequency region.]

redução para 2 e $5 \%$ de óxido de zinco, sendo que $2 \%$ de $\mathrm{ZnO}$ é aparentemente um valor limite para se obter menor valor de resistividade elétrica neste material.

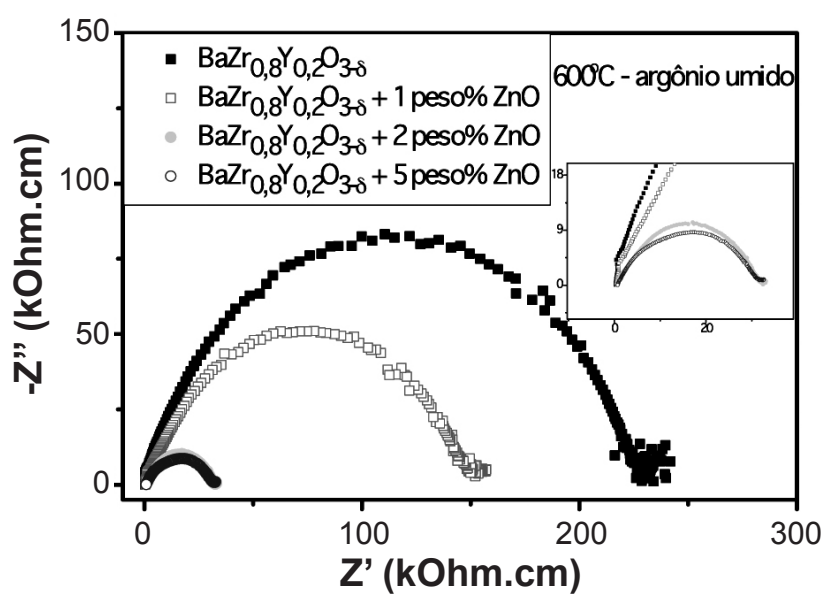

Figura 13: Diagramas de impedância de $\mathrm{BaZr}_{0,8} \mathrm{Y}_{0,2} \mathrm{O}_{3-\delta}$ com e sem $\mathrm{ZnO}$ em diferentes proporções, como aditivo de sinterização, medidos a $600{ }^{\circ} \mathrm{C}$ sob atmosfera de argônio úmido. Inserido um gráfico na região de altas freqüências.

[Figure 13: Impedance diagrams of $\mathrm{BaZr}_{0.8} \mathrm{Y}_{0.2} \mathrm{O}_{3-8}$ with and without $\mathrm{ZnO}$, measured at $600{ }^{\circ} \mathrm{C}$ under humid argon. Inset:high frequency region.]

Tabela III - Valores de resistividade elétrica a $600{ }^{\circ} \mathrm{C}$ de $\mathrm{BaZr}_{0,8} \mathrm{Y}_{0,2} \mathrm{O}_{3-\delta}$ sinterizados a $1500{ }^{\circ} \mathrm{C}$ ao ar, com diferentes aditivos.

[Table III - Electrical resistivity values of $\mathrm{BaZr}_{0.8} \mathrm{Y}_{0.2} \mathrm{O}_{3-8}$ at $600{ }^{\circ} \mathrm{C}$ of pellets sintered at $1500^{\circ} \mathrm{C}$, with different additives.]

\begin{tabular}{cc}
\hline Composição & $\rho(\mathrm{k} \Omega . \mathrm{cm})$ \\
\hline $\mathrm{BZY}$ & 211 \\
$\mathrm{BZY}+1$ peso $\% \mathrm{ZnO}$ & 120 \\
$\mathrm{BZY}+2$ peso $\% \mathrm{ZnO}$ & 31 \\
$\mathrm{BZY}+5$ peso $\% \mathrm{ZnO}$ & 30 \\
& \\
$\mathrm{BZY}+1$ peso $\% \mathrm{~B}_{2} \mathrm{O}_{3}$ & 38 \\
$\mathrm{BZY}+2$ peso $\% \mathrm{~B}_{2} \mathrm{O}_{3}$ & 48 \\
$\mathrm{BZY}+5$ peso $\% \mathrm{~B}_{2} \mathrm{O}_{3}$ & 2970 \\
\hline
\end{tabular}

AFig. 12 mostra os diagramas de impedância de zirconato de bário com e sem $\mathrm{ZnO}$, sinterizados a $1500{ }^{\circ} \mathrm{C}$ e medidos a $600{ }^{\circ} \mathrm{C}$, sob atmosfera de argônio seco. O objetivo deste experimento foi o de eliminar da câmara de medida tanto o ar quanto a umidade por meio da inserção contínua do gás. $\mathrm{O}$ 
oxigênio do ar poderia contribuir para o componente iônico (via vacâncias de oxigênio) para a condutividade elétrica. A umidade poderia contribuir para o componente protônico por meio da dissociação da água a $600{ }^{\circ} \mathrm{C}$ e o fornecimento de prótons para a condutividade elétrica. Os resultados não são muito diferentes dos obtidos ao ar. Comparando os valores de resistividade elétrica somente para o composto $\mathrm{BaZr}_{0,8} \mathrm{Y}_{0,2} \mathrm{O}_{3-\delta,}$, ao ar é $205 \mathrm{kOhm} . \mathrm{cm}$, sob argônio seco é $218 \mathrm{kOhm}$.cm e sob argônio úmido é $225 \mathrm{kOhm} . \mathrm{cm}$, valores próximos.

A Fig. 13 mostra os diagramas de impedância de zirconato de bário com e sem $\mathrm{ZnO}$, sinterizados a $1500{ }^{\circ} \mathrm{C}$ e medidos a $600{ }^{\circ} \mathrm{C}$, sob atmosfera de argônio úmido.

A Tabela III mostra os valores de resistividade elétrica dos compactos cerâmicos com e sem aditivos de sinterização, para medidas ao ar.

Os compactos cerâmicos de zirconato de bário dopado com ítrio, sinterizados após mistura com 2 e 5 peso $\%$ de $\mathrm{ZnO}$, apresentam os menores valores de resistividade elétrica.

\section{CONCLUSÕES}

Com o método de mistura de óxidos, para a síntese de pós de zirconato de bário dopado com ítrio, foram obtidos pós com distribuição bimodal das partículas e tamanho médio reduzido. $\mathrm{O}$ composto $\mathrm{BaZr}_{0,8} \mathrm{Y}_{0,2} \mathrm{O}_{3-\delta}$, obtido a partir deste método, sinteriza a $1500{ }^{\circ} \mathrm{C}$ e produz pastilhas com boa densificação, com aproximadamente $95 \%$ da densidade teórica, fazendo-se uso de aditivos de sinterização.As medidas de densidade mostraram que a maior densificação foi obtida com óxido de zinco nas proporções de 2 e 5 peso $\%$, atingindo aproximadamente $95 \%$ da densidade teórica. As medidas de resistividade elétrica evidenciaram a menor resistividade elétrica do composto cerâmico $\mathrm{BaZr}_{0,8} \mathrm{Y}_{0,2} \mathrm{O}_{3-\delta}$ com uso de 5 peso $\%$ de $\mathrm{ZnO}$, cuja densificação é aproximadamente $95 \%$ da densidade teórica. Os resultados de síntese, sinterização, densificação e resistividade elétrica mostram que óxido de boro e óxido de zinco foram eficientes para obter compostos com menores valores de resistividade elétrica.

\section{AGRADECIMENTOS}

À FAPESP (Proc. 05/53241-9), ao CNPq (Procs. 136530/2008-7, 562532/2008-0, 303414/2009-0). Ao Dr. J. R. Martinelli pelas medidas de distribuição de tamanho de partículas e a Y. V. França pelas medidas de análise térmica.

\section{REFERÊNCIAS}

[1] R. M. Dell, A. Hooper, in Solid electrolytes general principles, characterization, materials and applications, ed. P. Hagenmuller, Academic Press, New York, EUA (1978) 291.

[2] S. M. Haile, Acta Mater. 51 (2003) 5981.

[3] J. B. Goodenough, Ann. Rev. Mater. Res. 33 (2003) 91.

[4] S. M. Haile, Mater. Today 6 (2003) 24.
[5] K. Joon, J. Power Sources 71 (1998) 12.

[6] E. C. Subbarao, Solid electrolytes and their applications, New York, EUA (1980).

[7] O. Yamamoto, Electrochem. Acta 45 (2000) 2423.

[8] N. Q. Minh, J. Am. Ceram. Soc. 76, 3 (1993) 563.

[9] J. Milewski, A. Miller, J. Salacinski, Int. J. Hydrogen En. 32 (2007) 687.

[10] N. Q. Minh, Solid State Ionics 174 (2004) 271.

[11] H. Rickert, Electrochemistry of Solids, an Introduction, New York, EUA (1982).

[12] J. H. Lee, J. Mater. Sci. 38 (2003) 4247.

[13] T. Takeuchi, Sensors and Actuators 14 (1988) 109.

[14] Q. Liu, Solid State Ionics 86-88 (1996) 1037.

[15] H. Matsumoto, T. Shimura, H. Iwahara, T. Higuchi, K. Yashiro, A. Kaimai, T. Kawada, J. Mizusaki, J. Alloys Compd. 408-412 (2006) 456.

[16] A. Kruth, J. T. S. Irvine, Solid State Ionics 162-163 (2003) 83.

[17] W. G. Coors, D. W. Readey, J. Am. Ceram. Soc. 85 (2002) 2637.

[18] T. Higuchi, T. Tsukamoto, H. Matsumoto, T. Shimura, K. Yashiro, T. Kawada, J. Mizusaki, S. Shin, T. Hattori, Solid State Ionics 176 (2005) 2967.

[19] H. Iwahara, T. Esaka, H. Uchida, N. Maeda, Solid State Ionics 3-4 (1981) 359.

[20] T. Schober, W. G. Coors, Solid State Ionics 176 (2005) 357.

[21] K. D. Kreuer, Chem. Mater. 8 (1996) 610.

[22] A. Longo, F. Giannici, A. Balerna, C. Ingrao, F. Deganello, A. Martorana, Chem. Mater. 18 (2006) 5782.

[23] H. G. Bohn, T. Schober, J. Am. Ceram. Soc. 83 (2000) 768.

[24] P. Babilo, T. Uda, S. M. Haile, J. Mater. Res. 22 (2007) 1322.

[25] K. D. Kreuer, Solid State Ionics 125 (1999) 285.

[26] M. J. Scholten, J. Schoonman, J. C. V. Miltenburgh, H. A. J. Oonk, Solid State Ionics 61 (1993) 83.

[27] R. C. T. Slade, S. D. Flint, N. Singh, Solid State Ionics 82 (1995) 135.

[28] T. Norby, Solid State Ionics 125 (1999) 1.

[29] K. Katahira, Y. Kohchi, T. Shimura, H. Iwahara, Solid State Ionics 138 (2000) 91.

[30] K. H. Ryu, S. M. Haile, Solid State Ionics 125 (1999) 355.

[31] S. Wienstroer, H. D. Wiemhofer, Solid State Ionics 113 (1997) 101.

[32] K. D. Kreuer, St. Adams, W. Munch, A. Fuchs, U. Klock, J. Maier, Solid State Ionics 145 (2001) 295.

[33] F. Iguchi, T. Yamada, N. Sata, T. Tsurui, H. Yugami, Solid State Ionics 177 (2006) 2381.

[34] A. M. Azad, S. Subramaniam, T. W. Dung, J. Alloys Compd. 334 (2002) 118.

[35] H. Iwahara, T. Yajima, T. Hibino, K. Ozaki, H. Suzuki, Solid State Ionics 61 (1993) 65.

[36] M. Viviani, M. T. Buscaglia, V. Buscaglia, M. Leoni, P. Nanni, J. Eur. Ceram. Soc. 21 (2001) 1981.

[37] A. Manthiram, J. K. Kuo, J. B. Goodenough, Solid 
State Ionics 62 (1993) 225.

[38] M. Bucko, J. Oblakowski, J. Eur. Ceram. Soc. 27 (2007) 3625.

[39] K. D. Kreuer, Ann. Rev. Mater. Res. 33 (2003) 333. [40] A. Magrez, T. Schober T. Solid State Ionics 175 (2004) 585.

[41] P. Babilo, S. M. Haile, J. Am. Ceram. Soc. 88 (2005) 2362.

[42] J. R. Macdonald, Impedance Spectroscopy: Emphasizing solid materials and systems, New York, EUA (1987).

[43] I. R. Oliveira, A. R. Studart, M. D. M. Innocentini, L. A. Nascimento, V. C. Pandolfelli, Cerâmica 50, 313 (2004) 1. [44] Catálogo Alfa Aesar, Barium Oxide (2010).

[45] A. K. Azad, J. T. S. Irvine, Solid State Ionics 179 (2008) 678.

[46] S. W. Tao, J. T. S. Irvine, J. Solid State Chem. 180, 12 (2007) 3493.

Rec. 31/12/2010, Rev. 28/04/2011, Ac. 04/05/2011) 